\title{
Seizure and anticonvulsant outcomes following stereotactic radiosurgery for intracranial arteriovenous malformations
}

\author{
Colin J. Przybylowski, BS, ${ }^{1}$ Dale Ding, MD, ${ }^{1}$ Robert M. Starke, MD, MSc, ${ }^{1}$ Chun-Po Yen, MD, ${ }^{1}$ \\ Mark Quigg, MD, MSc, ${ }^{2}$ Blair Dodson, RN, BSN, ${ }^{1}$ Benjamin Z. Ball, BS, ${ }^{1}$ \\ and Jason P. Sheehan, MD, PhD ${ }^{1,3}$
}

\begin{abstract}
Departments of ${ }^{1}$ Neurological Surgery, ${ }^{2}$ Neurology, and ${ }^{3}$ Radiation Oncology, University of Virginia Health System, Charlottesville, Virginia
\end{abstract}

\begin{abstract}
OBJECT Epilepsy associated with arteriovenous malformations (AVMs) has an unclear course after stereotactic radiosurgery (SRS). Neither the risks of persistent seizures nor the requirement for postoperative antiepileptic drugs (AEDs) are well defined.

METHODS The authors performed a retrospective review of all patients with AVMs who underwent SRS at the University of Virginia Health System from 1989 to 2012. Seizure status was categorized according to a modified Engel classification. The effects of demographic, AVM-related, and SRS treatment factors on seizure outcomes were evaluated with logistic regression analysis. Changes in AED status were evaluated using McNemar's test.
\end{abstract}

RESULTS Of the AVM patients with pre- or post-SRS seizures, 73 with pre-SRS epilepsy had evaluable data for subsequent analysis. The median patient age was 37 years (range 5-69 years), and the median follow-up period was 65.6 months (range 12-221 months). Sixty-five patients (89\%) achieved seizure remission (Engel Class IA or IB outcome). Patients presenting with simple partial or secondarily generalized seizures were more likely to achieve Engel Class I outcome $(p=0.045)$. Twenty-one (33\%) of 63 patients tapered off of pre-SRS AEDs. The incidence of freedom from AED therapy increased significantly after SRS ( $p<0.001$, McNemar's test). Of the Engel Class IA patients who continued AED therapy, $54 \%$ had patent AVM nidi, whereas only $19 \%$ continued AED therapy with complete AVM obliteration $(p=0.05)$.

CONCLUSIONS Stereotactic radiosurgery is an effective treatment for long-term AVM-related epilepsy. Seizure-free patients on continued AED therapy were more likely to have residual AVM nidi. Simple partial or secondarily generalized seizure type were associated with better seizure outcomes following SRS.

http://thejns.org/doi/abs/10.3171/2014.11.JNS141388

KEY WORDS epilepsy; seizure; arteriovenous malformation; Gamma Knife radiosurgery; antiepileptic drug; obliteration; stereotactic radiosurgery

$\mathrm{S}$ TEREOTACTIC radiosurgery (SRS) is not only effective for the prevention of arteriovenous malformation (AVM)-associated hemorrhage, $, 3,4,6,7,15,16,23,26$ but is also effective in the treatment of AVM-associated epilepsy, with estimates ranging from $55 \%$ to $80 \%$ of patients who are seizure free after SRS (Table 1). ${ }^{8,9,14,22,23,25}$ However, detailed seizure outcomes are lacking in the majority of AVM series. Many studies, including a previous one from our Gamma Knife center, ${ }^{23}$ outline clinical seizure outcomes broadly without a thorough analysis of factors related to outcome. Additionally, the potentially long-term antiepileptic effects of SRS are not accounted for by most previous studies due to their relatively short follow-up durations.

In the current study, we evaluated a cohort of patients with AVM-related epilepsy who were treated with SRS at our institution. Our aims were to classify long-term postoperative seizure outcomes, determine antiepileptic drug

ABBREVIATIONS AED = antiepileptic drug; $\mathrm{AVM}=$ arteriovenous malformation; $\mathrm{Cl}$ = confidence interval; $\mathrm{DSA}=$ digital subtraction angiography; $\mathrm{GKRS}=\mathrm{Gamma}$ Knife radiosurgery; $\mathrm{OR}=$ odds ratio; $\mathrm{RIC}=$ radiation-induced change; $\mathrm{SRS}=$ stereotactic radiosurgery.

SUBMITTED June 20, 2014. ACCEPTED November 25, 2014

INCLUDE WHEN CITING Published online January 23, 2015; DOI: 10.3171/2014.11.JNS141388.

DISCLOSURE The authors report no conflict of interest concerning the materials or methods used in this study or the findings specified in this paper. 
TABLE 1. Literature summary of seizure remission after AVM SRS

\begin{tabular}{lcccc}
\hline \multicolumn{1}{c}{ Authors \& Year } & $\begin{array}{c}\text { No. of } \\
\text { Patients }\end{array}$ & $\begin{array}{c}\text { Follow-Up } \\
\text { Duration* }\end{array}$ & Outcome $\dagger$ & $\begin{array}{c}\text { Remission } \\
(\%)\end{array}$ \\
\hline $\begin{array}{l}\text { Heikkinen et al., } \\
1989 \ddagger\end{array}$ & 29 & $2-6$ yrs & Cessation & $16(55)$ \\
\hline $\begin{array}{l}\text { Steiner et al., 1992 } \\
\text { Gerszten et al., 1996§ }\end{array}$ & 15 & $4-96$ mos & Cessation & $41(69)$ \\
\hline Kurita et al., 1998 & 35 & 47 mos & Cessation & $11(73)$ \\
\hline $\begin{array}{l}\text { Schäuble et al., 2004 } \\
\text { Yang et al., 2012 }\end{array}$ & 65 & 4 yrs & $\begin{array}{c}\text { Engel Class } \\
\text { >IV }\end{array}$ & $48(74)$ \\
\hline Total & 86 & 7.5 yrs & SFS <3 & $66(77)$ \\
\hline
\end{tabular}

SFS = seizure frequency score.

* Reported as mean or range.

$\dagger$ Definition of clinical seizure improvement.

$\ddagger$ Proton beam accelerator (all other studies used Gamma Knife radiosurgery). $\S$ Pediatric patients only.

(AED) treatment regimens prior to and following SRS, and define demographic, AVM-related, and treatment-related factors associated with favorable seizure outcomes.

\section{Methods \\ Patient Population}

We performed a retrospective review of a prospectively maintained, institutional review board-approved database, containing 1145 patients treated with Gamma Knife radiosurgery (GKRS) for AVMs at the University of Virginia from 1989 to 2012. Patients were excluded from analysis if they did not experience seizures at any point, or experienced seizures but did not have detailed seizure outcomes data including seizure type, Engel classification, and AED therapy status. Patients were also excluded if their seizure outcomes were not able to be determined prior to any embolization or resection procedures after SRS.

We classified postoperative seizure outcomes into 3 groups according to modified Engel criteria: ${ }^{5}$ 1) absence of all seizures after SRS (Engel Class IA) for a duration of 1 year at any point after SRS; 2) absence of disabling seizures (seizures limited to simple partial seizures; Engel Class IB) for the same duration; or 3) patients with outcomes worse than Engel Class IA or IB (Engel Classes IIIV). Antiepileptic drug status was classified as either on or off AEDs, and the number of AEDs used. Factors evaluated included: 1) demographic and patient history data, including age at SRS, sex, pre-SRS embolization, pre-SRS resection, focal neurological deficit on presentation, seizure types (secondarily generalized, simple partial, and complex partial), and follow-up duration; 2) AVM-related factors, including volume, maximum diameter, pre-SRS hemorrhage, location, and post-SRS hemorrhage; and 3) treatment-related factors, including margin dose, number of isocenters, radiation-induced change (RIC), post-SRS cyst formation, and AVM obliteration.

\section{Gamma Knife Radiosurgery Technique}

Our institution's radiosurgical technique for the treat- ment of AVMs has been previously described ${ }^{23}$ The AVM nidus is defined by a combination of digital subtraction angiography (DSA) and MRI. Prior to 1991, MRI was not routinely used for treatment planning. Either Leksell GammaPlan software (after June 1994; Elekta AB) or Kula software (before June 1994) was used. Computed tomography was used when MRI was contraindicated (e.g., in a patient with a pacemaker).

\section{Follow-Up}

Patients were followed-up every 6 months for the first 2 years after treatment, and then annually thereafter. Follow-up evaluation was performed preferentially at the University of Virginia. If patients were unable to travel to our institution, follow-up imaging and neurological status were obtained in correspondence with outside referring hospitals and patients' local primary care physicians. All imaging studies were reviewed by a University of Virginia neurosurgeon and neuroradiologist. DSA was used to confirm AVM obliteration only after MRI or CT demonstrated absence of a residual lesion. Obliteration was defined by the absence of flow voids on MRI/CT or absence of pathological arteriovenous shunting on DSA. Additional imaging, including CT or MRI, was performed in the setting of neurological deterioration. Radiation-induced change was defined radiologically as perinidal T2 hyperintensity on MRI. Clinical correlation in patients experiencing headaches, seizures, and/or focal neurological deficits established symptomatic RIC.

\section{Statistical Analysis}

Univariate analysis was performed using the unpaired t-test (continuous) or Fisher's exact test (categorical). Significant factors in univariate analysis $(\mathrm{p}<0.15)^{1}$ were entered into a multivariate logistic regression analysis. Interaction and confounding were assessed through stratification and relevant expansion covariates. Changes in AED status (continuing or discontinuing AEDs) were evaluated with McNemar's test, and p values $<0.05$ were considered statistically significant. Statistical analysis was conducted using Stata (version 10.0, StataCorp LP).

\section{Results}

\section{Seizure Outcomes}

Based on our exclusion criteria, 885 patients were excluded for lack of seizures and 181 patients were excluded for lack of detailed seizure outcomes. Seventy-three patients had pre-SRS epilepsy with sufficient data for analysis (Fig. 1). The median patient age was 37 years (range 5-69 years). The mean clinical follow-up duration was 78.2 months (6.5 years), the median was 65.6 months (5.5 years), and the range was 12 to 220 months (1-18 years).

As Fig. 2 demonstrates, outcomes in seizure status and AED status typically occurred in a similar manner, i.e., seizure improvement translated to AED status improvement for patients. A total of 65 patients (89\%) experienced either complete seizure cessation (Engel Class IA, $n=36$; $49 \%$ ) or had only nondisabling auras or simple partial seizures (Engel Class IB, $\mathrm{n}=29 ; 40 \%$ ).

Table 2 shows a comparison of factors as functions of 


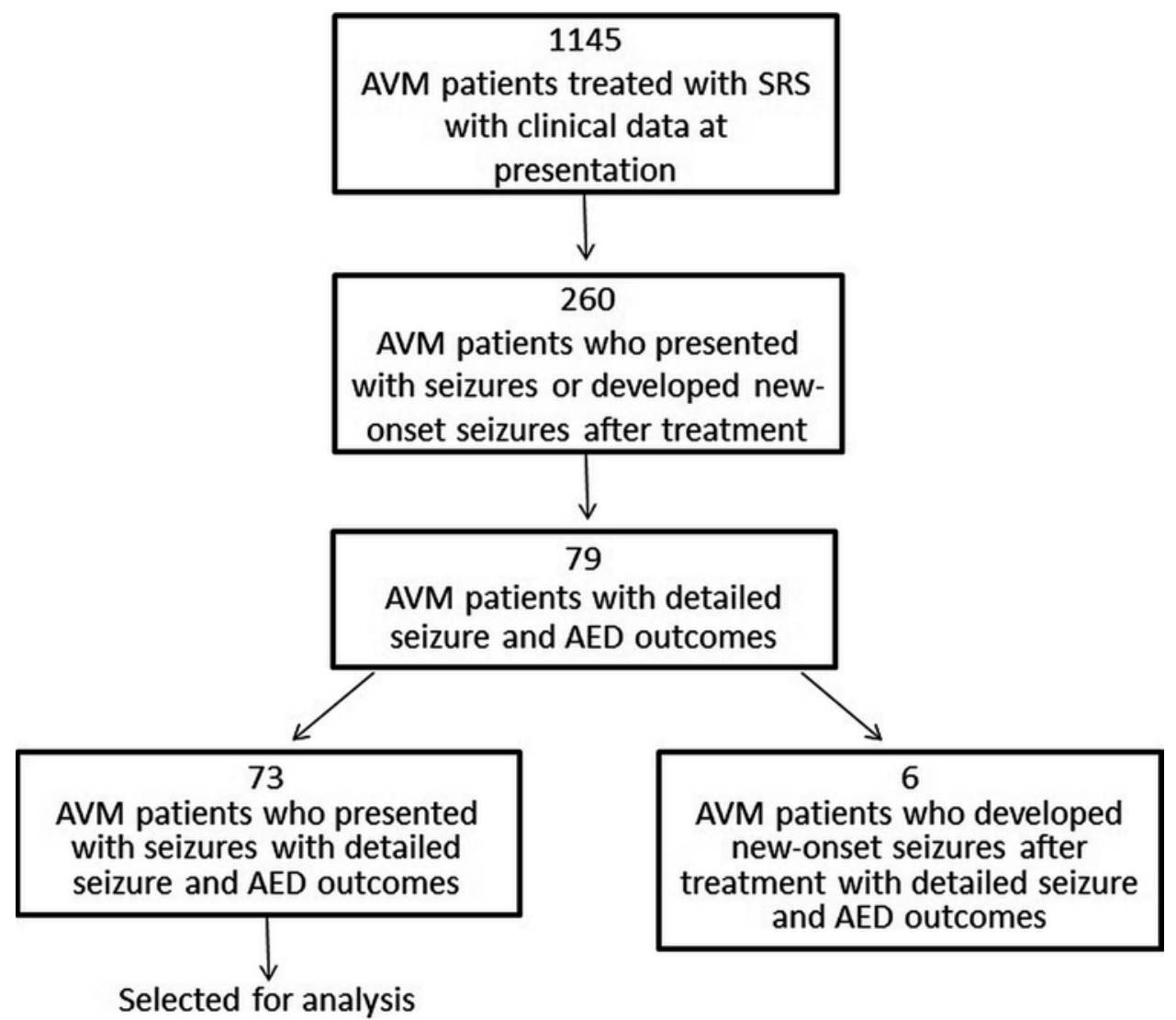

FIG. 1. Flowchart showing the selection process for analysis based on this study's inclusion and exclusion criteria.

seizure outcomes in univariate analysis (Engel Class IA or IB vs Engel Classes II-IV). The presence of seizures other than complex partial seizures $(p=0.07)$, longer duration of follow-up ( $p=0.12)$, and AVM location other than frontal $(p=0.10)$ were associated with Engel Class I outcome.

No SRS treatment factors predicted outcome. The mean \pm SD radiological follow-up period was $75 \pm 54$ months for MRI and $46 \pm 33$ months for DSA. AVM obliteration was observed in 58\% of patients (MRI only in 10 cases [14\%], DSA in 32 cases [44\%]). However, AVM obliteration did not predict seizure outcome. Neither post-SRS hemorrhage nor cyst formation predicted seizure outcome. Radiationinduced changes were diagnosed in 43 patients (59\%) at a median interval following treatment of 11.1 months (range 0-144.7 months). Eleven patients with RICs (15\%) were symptomatic. Of these 11 patients, 4 (with pre-SRS epilepsy; 5.5\%) had provoked seizures based on the timing of seizures and RIC. Permanent worsening of seizures as a result of RICs was not observed. Additionally, 5 patients (7\%) had focal neurological deficits and 2 patients (3\%) had headaches. RIC-related symptoms were permanent in 2 patients (3\%), both of whom developed hemiparesis.

Significant factors from univariate analyses were evaluated with multivariate logistic regression (Table 3 ). Patients presenting with simple partial or secondarily generalized seizures were 13 times more likely to achieve seizure remission than those with complex partial seizures $(\mathrm{p}=0.045)$. Follow-up duration and AVM location were not significant in the multivariate model.
Not all patients had pre-SRS epilepsy; 6 patients experienced new-onset seizures after SRS. Of the 6 patients, 3 had parietal lobe AVMs, 2 had temporal lobe AVMs, and 1 had a brainstem AVM. Three $(50 \%)$ of these 6 patients had undergone pre-SRS resection, compared with 3 (4\%)

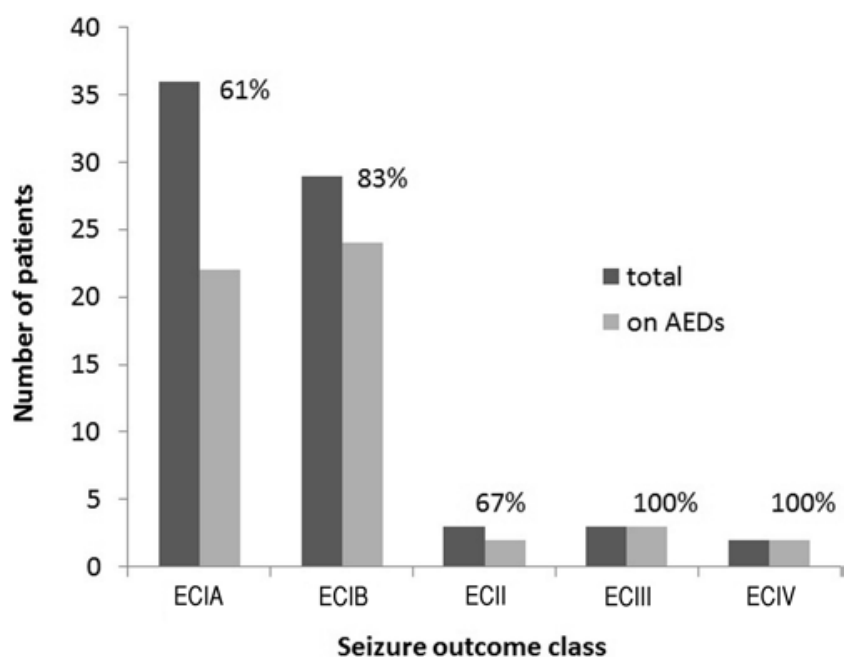

FIG. 2. Distributions of seizure outcomes by AED status after SRS. Percentages note the proportion of patients taking AEDs within each class. Engel Class (EC)IA = complete remission; $E C I B=$ remission from disabling seizures or residual simple partial seizures; $E C I I=$ rare disabling seizures; ECIII = significant improvement; ECIV = no improvement. 
TABLE 2. Univariate analysis of seizure outcomes after GKRS for AVMs*

\begin{tabular}{|c|c|c|c|c|}
\hline \multirow[b]{2}{*}{ Variable } & \multirow[b]{2}{*}{ Total Patients } & \multicolumn{2}{|c|}{ Engel Class } & \multirow[b]{2}{*}{ p Value } \\
\hline & & IA or IB & II-IV & \\
\hline No. of patients & 73 & 65 & 8 & \\
\hline Mean age \pm SD (yrs) & & $38 \pm 13$ & $32 \pm 18$ & 0.25 \\
\hline Sex (male) & 38 & $54 \%$ & $37.5 \%$ & 0.39 \\
\hline Pre-SRS embolization & 22 & $29 \%$ & $37.5 \%$ & 0.63 \\
\hline Pre-SRS resection & 3 & $5 \%$ & $0 \%$ & 0.53 \\
\hline Focal neurological deficit & 5 & $6 \%$ & $12.5 \%$ & 0.51 \\
\hline \multicolumn{5}{|l|}{ Pre-SRS predominant seizure type } \\
\hline Secondarily generalized seizures & 37 & $51 \%$ & $50 \%$ & 0.74 \\
\hline Simple partial seizures & 25 & $35 \%$ & $25 \%$ & 0.70 \\
\hline Complex partial seizures & 4 & $3 \%$ & $25 \%$ & $0.07 \ddagger$ \\
\hline Unknown seizure type & 7 & & & \\
\hline Mean clinical follow-up \pm SD (mos) & & $81 \pm 51$ & $50 \pm 50$ & $0.12 \ddagger$ \\
\hline Mean AVM volume $\pm \mathrm{SD}\left(\mathrm{cm}^{3}\right)$ & & $6 \pm 7$ & $4 \pm 3$ & 0.57 \\
\hline Mean AVM maximum diameter \pm SD $(\mathrm{cm})$ & & $2.7 \pm 1$ & $2.7 \pm 8$ & 0.98 \\
\hline Pre-SRS hemorrhage & 13 & $18.5 \%$ & $12.5 \%$ & 0.68 \\
\hline \multicolumn{5}{|l|}{ AVM location } \\
\hline frontal lobe & 23 & $28 \%$ & $62.5 \%$ & \\
\hline parietal lobe & 21 & $29 \%$ & $25 \%$ & \\
\hline temporal lobe & 19 & $28 \%$ & $12.5 \%$ & \\
\hline occipital lobe & 7 & $11 \%$ & $0 \%$ & \\
\hline deept & 2 & $3 \%$ & $0 \%$ & \\
\hline insula & 1 & $1.5 \%$ & $0 \%$ & \\
\hline AVM location other than frontal & 50 & $72 \%$ & $37.5 \%$ & $0.10 \ddagger$ \\
\hline Post-SRS hemorrhage & 3 & $3 \%$ & $12.5 \%$ & 0.24 \\
\hline Mean margin dose \pm SD (Gy) & & $21 \pm 3$ & $21 \pm 5$ & 0.99 \\
\hline Mean no. of isocenters \pm SD & & $5 \pm 5$ & $6 \pm 5$ & 0.78 \\
\hline $\mathrm{RICs}$ & 43 & $58 \%$ & $62.5 \%$ & 0.83 \\
\hline Post-SRS cyst formation & 2 & $3 \%$ & $0 \%$ & 0.62 \\
\hline AVM obliteration & 42 & $60 \%$ & $37.5 \%$ & 0.24 \\
\hline \multicolumn{5}{|l|}{ Mean radiological follow-up $\pm \mathrm{SD}$ (mos) } \\
\hline DSA & & $48 \pm 35$ & $28 \pm 11$ & 0.16 \\
\hline MRI & & $76 \pm 52$ & $48 \pm 51$ & 0.17 \\
\hline
\end{tabular}

of 73 in the pre-SRS epilepsy group $(\mathrm{p}<0.01$, Fisher's exact test). The SRS treatment parameters in these 6 patients (margin dose, maximum dose, isocenters, and percentage isodose) were similar to the pre-SRS epilepsy group. Two of 6 patients were observed to have mild, transient RICs. In 1 patient, RIC was believed to have provoked the newonset seizures. Two (33\%) of these 6 patients experienced latency-period hemorrhages, compared with $3(4 \%)$ of 73 patients with pre-SRS epilepsy ( $\mathrm{p}=0.04$, Fisher's exact test). The seizure types were simple partial in 3 cases and unknown in the other 3 cases. After a median follow-up of 100 months (range 51-192 months), the AVMs in 4 of these 6 patients were obliterated, and all 6 were maintained on AED therapy. All 6 patients achieved seizure remission with AEDs.

\section{Antiepileptic Drug Status}

When AED status was included in the multivariate analysis for independent predictors of Engel Class I outcome (Table 3), its odds ratio (OR) did not reach statistical significance. Because the majority of patients experienced seizure remission, accordingly many were treated with fewer AEDs (Fig. 3). At last follow-up, 28 patients (38\%) were off AEDs, including 21 (33\%) of 63 patients who were able to taper off pre-SRS AEDs completely. The incidence of freedom from AED therapy increased significantly after SRS ( $p<0.001$, McNemar's test).

Patients fell into 2 groups based on pre-SRS AED status. Ten of the 73 patients in the sample were not treated with AEDs prior to SRS. Seven of these patients, whose seizures were limited to simple partial seizures, were nev- 
TABLE 3. Multivariate analysis of Engel Class I outcome after GKRS for AVMs

\begin{tabular}{|c|c|c|c|}
\hline Variable & $O R^{*}$ & $95 \% \mathrm{Cl}^{*}$ & $\mathrm{p}$ Value \\
\hline $\begin{array}{l}\text { Simple partial or secondarily generalized } \\
\text { seizures }\end{array}$ & 13 & $1.1-153$ & $0.045 \dagger$ \\
\hline Increasing clinical follow-up & 1.0 & $0.99-1.0$ & 0.07 \\
\hline Location other than frontal & 2.7 & $0.32-22$ & 0.37 \\
\hline
\end{tabular}

er treated with AEDs. Six of these 7 patients experienced complete remission while 1 remained with simple partial seizures. Three of the 10 AED-naive patients were started on AEDs after SRS. One of these patients experienced complete remission (Engel Class IA), while the other 2 experienced auras only (Engel Class IB).

Sixty-three patients of the total sample were treated with AEDs before SRS. Twenty-nine (46\%) of these patients experienced complete seizure remission after SRS (Engel Class IA). Although seizure outcome was the same in this group, 16 had AEDs discontinued (55\%) and 13 (45\%) remained on AEDs. Those on and off AEDs despite cessation of seizures did not differ by sex, age, preSRS embolization, prior hemorrhage, nidus volume, AVM location, SRS treatment parameters, or presence of RICs $(p>0.05)$. However, the presence of a residual nidus appeared to influence the decision to continue AED treatment. Whereas $54 \%$ of patients with a residual nidus remained on treatment, only $19 \%$ with no remaining nidus continued AED therapy ( $\mathrm{p}=0.05$, Fisher's exact test).

\section{Further AVM Treatment}

During follow-up, 13 patients (18\%) underwent repeat SRS for incompletely obliterated AVMs. Four patients $(5.5 \%)$ underwent additional embolization for large residual nidi. No patients in our sample underwent post-SRS AVM resection or additional surgical intervention (such as CSF diversion) for RICs or postradiosurgery cyst formation.

\section{Discussion}

This is the first study to report detailed seizure and AED outcomes following SRS for AVM-associated epilepsy. The relatively long follow-up period of this study compared with previous studies more accurately reflects the potentially long-term antiepileptic mechanism of SRS. The most important findings are that seizures remit at a high rate in long-term follow-up, and many patients are able to decrease or discontinue AED therapy. Seizure type (simple partial or secondarily generalized) predicted seizure remission. Stereotactic radiosurgery parameters, nidus obliteration, RICs, and post-SRS hemorrhage did not predict seizure remission in those with pre-SRS epilepsy. However, RICs, prior surgery, or post-SRS hemorrhage may be important in the few patients with new-onset seizures after SRS. Finally, AED discontinuation patterns followed seizure remission. No particular factors were as-

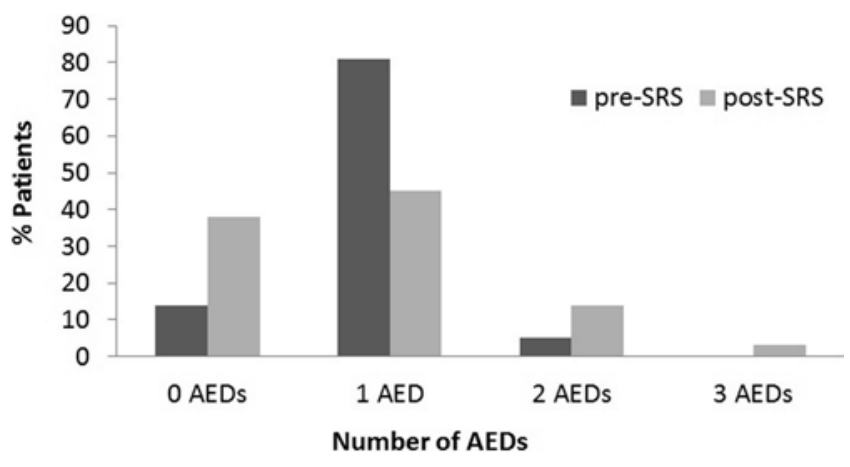

FIG. 3. Distribution of AED changes expressed in the proportion of patients taking 0-3 AEDs before and after SRS.

sociated with continuation of AEDs in those with complete seizure control other than persistence of a nidus after SRS.

Although seizures are the second most common clinical manifestation of AVMs, hemorrhage, rather than seizure control, is often the primary focus of AVM treatment. ${ }^{10}$ Intractable seizures, however, are associated with significant morbidities in terms of underemployment, quality of life, and problems with mood and cognition..$^{13}$ Thus, the optimal intervention contributes to both nidus obliteration and seizure control. While complete microsurgical resection is the gold standard of AVM therapy, SRS has gained favor as a minimally invasive approach for nidi in deep or eloquent cortical areas, patients with medical comorbidities that place them at high surgical risk, and patients who refuse resection.

Our results suggest that SRS offers effective long-term AVM-related seizure control. In comparison with previous studies (Table 1), a relatively high proportion of patients (89\%) achieved seizure remission (Engel Class IA or IB), although our rate of complete seizure remission (Engel Class IA, 49\%) is comparable to those previously reported. One possible explanation for our results-beyond differences in methodology and definitions-is that our follow-up period (median 65.6 months) was longer than most other studies. Longer follow-up may allow more time to establish an effective AED regimen or to permit long-term antiepileptic SRS effects to develop. We note that in the present study, patients with longer clinical follow-up trended toward better seizure control $(\mathrm{p}=$ 0.07 ). Additionally, we note that the preponderance of our cohort was treated after 1995 . A potentially important difference between the present and earlier studies is that the number of FDA-approved AEDs available has increased markedly. Before 1994, only 4 AEDs for partial epilepsy were in common use, i.e., phenobarbital, phenytoin, carbamazepine, and valproate; since then, more than 20 are now available in the US. Different AED regimens may thus contribute to the favorable seizure outcomes in this study.

It is not clear why those with simple partial or secondarily generalized seizures, rather than complex partial seizures, were more likely to achieve seizure control. The results of the present study agree with those from 2 earlier patient series that found that those with tonic-clonic seizures were more likely to experience seizure remission, 
although these studies included a mix of patients who underwent surgery and SRS..$^{11,12}$

The findings in the present study agree with those in earlier studies documenting that AVM obliteration is not requisite for seizure remission, ${ }^{8,23}$ but it conflicts with other studies that have endorsed improved seizure outcomes with obliteration. . $11,12,24,25$ In addition to nidus obliteration, SRS may contribute to seizure control via antiepileptic effects on the surrounding parenchyma. These effects include "nondestructive" neuromodulation and the formation of a perinidal gliotic capsule. ${ }^{19-21,25}$ We note that residual nidi after SRS were associated with AED continuation in the subset of seizure-free patients. We propose that continuation of AEDs in this subset arises from clinical caution rather than any difference in pathophysiology.

Our results of excellent remission rates after SRS show more favorable results for SRS than a recent meta-analysis of AVM-associated seizures. Baranoski et al. ${ }^{2}$ compared the seizure rates after SRS, surgery, and embolization. Whereas overall seizure remission-regardless of AVM obliteration-after SRS (63\%) was lower than in the present study and stood midway between that of surgery $(78 \%)$ and embolization (49\%), seizure remission with obliteration after SRS (85\%) was similar to the present study. Our results are also in contrast to those of Wang et al., ${ }^{24}$ who found that seizure outcomes differed by both pre-SRS epilepsy and mode of treatment. Those with pretreatment epilepsy were at greater risk for post-SRS epilepsy compared with those who underwent surgery. In contrast, those without AVM-associated epilepsy were at greater risk of developing new-onset seizures after surgery than after SRS. These results suggest that future studies may need to evaluate preoperative epilepsy status. However, our findings of low rates of chronic epilepsy after SRS suggest that large numbers of patients will be required for appropriate evaluation, given the low rate of persistent AVM-associated intractable seizures.

Our study is limited by its retrospective nature with inherent selection and treatment biases associated with the treatment physicians at our institution. In addition, the analyzed group in this study represents a minority of the patients with AVMs treated with SRS at our institution. We note, however, that high rates of seizure remission are less likely to be a result of follow-up loss because those with continuing seizures would be more likely to be evaluated reliably. Seizure remission was not predefined among the various referring physicians, and interobserver classifications of seizure control may differ. However, our conservative definitions of seizure remission for a defined time period are more rigorous than most previous studies that did not usually define seizure outcomes according to validated classifications. Finally, not all AVM obliterations were documented by angiography. While DSA is the gold standard to evaluate AVM obliteration, MRI has been shown to have relatively similar sensitivity and specificity for detecting AVM obliteration compared with DSA. ${ }^{17,18}$

\section{Conclusions}

Stereotactic radiosurgery is an effective treatment modality for long-term seizure control in patients with AVMs. Antiepileptic drug status correlated with seizure outcomes, and seizure-free patients on continued AEDs had residual AVM nidi. Patients presenting with simple partial or secondarily generalized seizures were significantly more likely to achieve seizure control following SRS.

\section{References}

1. Altman DG: Practical Statistics for Medical Research. Boca Raton, FL: Chapman \& Hall/CRC, 1999

2. Baranoski JF, Grant RA, Hirsch LJ, Visintainer P, Gerrard JL, Günel M, et al: Seizure control for intracranial arteriovenous malformations is directly related to treatment modality: a meta-analysis. J Neurointerv Surg 6:684-690, 2014

3. Ding D, Yen CP, Xu Z, Starke RM, Sheehan JP: Radiosurgery for low-grade intracranial arteriovenous malformations. J Neurosurg 121:457-467, 2014

4. Ding D, Yen CP, Xu Z, Starke RM, Sheehan JP: Radiosurgery for patients with unruptured intracranial arteriovenous malformations. J Neurosurg 118:958-966, 2013

5. Engel JJ, Van Ness P, Rasmussen T, Ojemann L: Outcome with respect to epileptic seizures, in Engel JJ (ed): Surgical Treatment of the Epilepsies, ed 2. New York: Raven Press, 1993, pp 609-621

6. Fokas E, Henzel M, Wittig A, Grund S, Engenhart-Cabillic R: Stereotactic radiosurgery of cerebral arteriovenous malformations: long-term follow-up in 164 patients of a single institution. J Neurol 260:2156-2162, 2013

7. Friedman WA, Bova FJ: Radiosurgery for arteriovenous malformations. Neurol Res 33:803-819, 2011

8. Gerszten PC, Adelson PD, Kondziolka D, Flickinger JC, Lunsford LD: Seizure outcome in children treated for arteriovenous malformations using gamma knife radiosurgery. Pediatr Neurosurg 24:139-144, 1996

9. Heikkinen ER, Konnov B, Melnikov L, Yalynych N, Zubkov Yu N, Garmashov Yu A, et al: Relief of epilepsy by radiosurgery of cerebral arteriovenous malformations. Stereotact Funct Neurosurg 53:157-166, 1989

10. Hofmeister C, Stapf C, Hartmann A, Sciacca RR, Mansmann $\mathrm{U}$, terBrugge K, et al: Demographic, morphological, and clinical characteristics of 1289 patients with brain arteriovenous malformation. Stroke 31:1307-1310, 2000

11. Hoh BL, Chapman PH, Loeffler JS, Carter BS, Ogilvy CS: Results of multimodality treatment for 141 patients with brain arteriovenous malformations and seizures: factors associated with seizure incidence and seizure outcomes. Neurosurgery 51:303-311, 2002

12. Hyun SJ, Kong DS, Lee JI, Kim JS, Hong SC: Cerebral arteriovenous malformations and seizures: differential impact on the time to seizure-free state according to the treatment modalities. Acta Neurochir (Wien) 154:1003-1010, 2012

13. Jones JE, Berven NL, Ramirez L, Woodard A, Hermann BP: Long-term psychosocial outcomes of anterior temporal lobectomy. Epilepsia 43:896-903, 2002

14. Kurita H, Kawamoto S, Suzuki I, Sasaki T, Tago M, Terahara A, et al: Control of epilepsy associated with cerebral arteriovenous malformations after radiosurgery. J Neurol Neurosurg Psychiatry 65:648-655, 1998

15. Lunsford LD, Kondziolka D, Flickinger JC, Bissonette DJ, Jungreis CA, Maitz AH, et al: Stereotactic radiosurgery for arteriovenous malformations of the brain. J Neurosurg 75:512-524, 1991

16. Maruyama K, Koga T, Shin M, Igaki H, Tago M, Saito N: Optimal timing for Gamma Knife surgery after hemorrhage from brain arteriovenous malformations. J Neurosurg 109 Suppl:73-76, 2008

17. O'Connor TE, Friedman WA: Magnetic resonance imaging assessment of cerebral arteriovenous malformation obliteration after stereotactic radiosurgery. Neurosurgery 73:761766,2013 
18. Pollock BE, Kondziolka D, Flickinger JC, Patel AK, Bissonette DJ, Lunsford LD: Magnetic resonance imaging: an accurate method to evaluate arteriovenous malformations after stereotactic radiosurgery. J Neurosurg 85:1044-1049, 1996

19. Quigg M, Rolston J, Barbaro NM: Radiosurgery for epilepsy: clinical experience and potential antiepileptic mechanisms. Epilepsia 53:7-15, 2012

20. Régis J, Bartolomei F, Hayashi M, Chauvel P: Gamma Knife surgery, a neuromodulation therapy in epilepsy surgery! Acta Neurochir Suppl 84:37-47, 2002

21. Régis J, Kerkerian-Legoff L, Rey M, Vial M, Porcheron D, Nieoullon A, et al: First biochemical evidence of differential functional effects following Gamma Knife surgery. Stereotact Funct Neurosurg 66 (Suppl 1):29-38, 1996

22. Schäuble B, Cascino GD, Pollock BE, Gorman DA, Weigand S, Cohen-Gadol AA, et al: Seizure outcomes after stereotactic radiosurgery for cerebral arteriovenous malformations. Neurology 63:683-687, 2004

23. Steiner L, Lindquist C, Adler JR, Torner JC, Alves W, Steiner M: Clinical outcome of radiosurgery for cerebral arteriovenous malformations. J Neurosurg 77:1-8, 1992

24. Wang JY, Yang W, Ye X, Rigamonti D, Coon AL, Tamargo $\mathrm{RJ}$, et al: Impact on seizure control of surgical resection or radiosurgery for cerebral arteriovenous malformations. Neurosurgery 73:648-656, 2013

25. Yang SY, Kim DG, Chung HT, Paek SH: Radiosurgery for unruptured cerebral arteriovenous malformations: long-term seizure outcome. Neurology 78:1292-1298, 2012

26. Yen CP, Sheehan JP, Schwyzer L, Schlesinger D: Hemorrhage risk of cerebral arteriovenous malformations before and during the latency period after GAMMA knife radiosurgery. Stroke 42:1691-1696, 2011

\section{Author Contributions}

Conception and design: Sheehan, Przybylowski, Ding, Yen, Quigg. Acquisition of data: Przybylowski, Yen, Dodson, Ball. Analysis and interpretation of data: Sheehan, Przybylowski, Ding, Starke, Quigg, Dodson, Ball. Drafting the article: Przybylowski, Ding, Starke, Yen, Quigg. Critically revising the article: Sheehan, Przybylowski, Ding, Starke, Yen, Quigg. Reviewed submitted version of manuscript: Sheehan, Przybylowski, Ding, Starke, Yen, Quigg. Approved the final version of the manuscript on behalf of all authors: Sheehan. Statistical analysis: Starke, Quigg.

\section{Correspondence}

Jason P. Sheehan, Department of Neurological Surgery, Box 800212, University of Virginia Health System, Charlottesville, VA 22908. email: jsheehan@virginia.edu. 